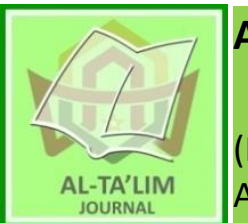

AL-TA'LIM JOURNAL, 25 (3), 2018, (182-198)

(Print ISSN 1410-7546 Online ISSN 2355-7893)

Available online at http://journal.tarbiyahiainib.ac.id/index.php/attalim

\title{
Educational Activity in Islamic Education: Evaluation of Hadith Course for First Intermediate Grade in Kingdom of Saudi Arabia
}

\author{
Received: $07^{\text {th }}$ July 2018; Revised: $04^{\text {th }}$ September 2018; Accepted: $26^{\text {th }}$ November 2018 \\ Permalink/DOI: http://dx.doi.org/10.15548/jt.v25i3.496
}

\author{
Salem Ali al-Qahtani *) \\ University of Malaya, Kuala Lumpur, \\ Malaysia \\ E-mail: $\underline{\text { salem@gmail.com }}$
}

\section{Asyraf Isyraqi Jamil}

University of Malaya, Kuala Lumpur, Malaysia

E-mail: isyraqi@um.edu.my

\section{Fakhrul Adabi Abdul Kadir}

University of Malaya, Kuala Lumpur, Malaysia

E-mail: fakhruladabi@um.edu.my

\section{*) Corresponding Author}

\begin{abstract}
The objective of this research is to determine how far the general objectives of teaching the subject of Hadith for the first intermediate grade have been achieved. The main question of this study is how adequate the educational activities in achieving the general objectives of teaching the subject of Hadith for the first intermediate grade. The study has used analytical descriptive approach to answer the questions of research. The tool of research is an analysis card which contains 52 educational activities; the sample of research. The study came to results which are: 1) the criteria laid down for the study were highly verified and the average was (3.50),2) achieving the axis of the study that represented the tool was arranged by the criteria related to the form of knowledge which highly verified and the average was (3.87) and the criteria related to the general objectives of teaching the subject of Hadith which highly verified and the average was (3.43), and 3) The criteria related to the activities and their general ways were highly verified and the average was (3.13). Some of the most important recommendations of the study are to increase the quorum of Hadith to two classes per week, to care of educating students about the concept of activity and the difference between it and the content and the benefit of each of them to students, in a language that can be understood simply by the students, to differentiate between activities of male students and female students after uniting the content which is better that the activities become to each sex according to what is suitable to nature and characteristic, and to form special committees or appointing educational supervisors whose first task is to follow up educational activities in the Islamic religious courses, and evaluating them, and then help the teacher and students to pass everything can be difficult to achieve these activities.
\end{abstract}

Keywords: Educational Activities; Islamic Education; Islamization of Knowledge; Kingdom of Saudi Arabia.

How to cite: al-Qahtani, S., Jamil, A., \& Kadir, F. (2018). Educational activity in Islamic education: Evaluation of hadith course for first intermediate grade in Kingdom of Saudi Arabia. Al-Ta Lim Journal, 25(3). doi:http://dx.doi.org/10.15548/jt.v25i3.496

\section{INTRODUCTION}

Since the educational activities are considered as a part of the curriculum and one of its pillars, in its modern concept, they will be one of the axes of making this experience. It is noticeable that after the middle of the nineteenth century, the perspective of the curricula has changed and the learner became the axis and the focus, rather than being only the material and information (Goodlad, 2013; Jacobs, 2004, 2010; Kam, Greenberg, \& Walls, 2003). In 1956, Krug pointed out that the curriculum is all the means that are 
implemented in the school in order to provide students with the appropriate opportunities to go through the desirable educational experiences (Rosen, 2008). When the curriculum was known with this concept, there was who made the educational activities among its basics, as this was common among educators in the second half of the nineteenth century. (Millar, 2002) stated that the curriculum is a set of direct and indirect educational experiences prepared by society to educate and prepare individuals in the environmental conditions.

When the curriculum, in its modern concept, included four pillars, on which it was based, namely, objectives, content, activity and evaluation, the content was the educational material that achieves the objectives of the curriculum, however, the academic content is not sufficient in itself to meet all the requirements of the student such as experiences and attitudes. Time also is not enough and sufficient to teach the students all this knowledge in the classroom, so the activity was the integral part of this process, especially in the field of Islamic Education. This was confirmed by the results of numerous studies, which proved that there are several benefits realized during practicing the educational activity in the field of Islamic Education. The study of Salem (1423AH) proved the link between the academic achievement and the interaction with activities. This confirms that activity is the core of the educational work, and not just a secondary factor of no value.

Hence, the significance and impact of the educational activities are clear. This significance is increasing with the curricula of Islamic religious sciences in Kingdom of Saudi Arabia, which are a key pillar of education and learning, which are perceived as one of the fundamentals upon which the statehood is build and which build a welleducated and good human being (Al-Sadan, 2000; Prokop, 2003; Rugh, 2002; Sedgwick, 2001; Shea \& Al-Ahmed, 2006). Ministry of Education in Kingdom of Saudi Arabia concerns to develop these curricula in a manner consistent with the Kingdom's mission and its leading role in the Islamic world. The Curriculum Development Project emanated from the education policy in the Kingdom, up-to-date with the internal and global changes and meeting the objectives of education and learning (Curriculum Document of Islamic religious sciences materials for the elementary and intermediate stages in General Education in 2006). The difference was clear and evident in the recent development, which included enhancing the student role in learning, singling out the educational activities in the Islamic religious sciences books, in a separate book, linking the curriculum to the learner's real life, adding enrichment information, the new issuing of the student book, and approving printing of a complete guide for the teacher that contributes to the development of the teacher's performance with what is required from them during their teaching.

Because activities are one of the most important key elements in the curriculum, and because of the absence of previous scientific studies that, to the best of the researcher's knowledge, deal with the criteria of the educational activities in the curricula of the Islamic religious sciences materials in Kingdom of Saudi Arabia, it was determined, after God's help and blessings, to find out the extent to which these criteria are applicable to the activities of this course, and attempt to scientifically study them, which may contribute to the development of these curricula.

From what the researcher experienced through his work in the Ministry of Education, along with asking and surveying a number of teachers who teach Hadith course, the constant question asked by the teachers was: What are the criteria upon which the activities were built? And whether it is one axis, or a number of axes, from which these criteria can be emanated? So it was important to find out what are these criteria that can be devised, and also find out whether these activities are based on scientific bases related to the student's real life, thus, they have a real 
impact on making their experiences, as the real activity is what the student does to learn, rather than what the teacher does to teach the student (Saadah and Ahmad, 2004).

It is important to establish a scientific basis to which we can invoke. It is not appropriate for the field experiences to be the only basis to which we can invoke. Establishing a scientific basis will also facilitate the evaluation and improvement of these activities, especially when we consider these experiences as one of the pillars of the curriculum in its modern concept (Salehi, Davari, \& Yunus, 2015; Yahya et al., 2017). The problem arises from the following question: To what extent are the criteria of educational activities applicable to the Hadith activities for the first intermediate grade?

The most significant objectives that are hoped to be achieved through this research are as follow: laying down criteria for selecting educational activities in the Islamic religious sciences materials; emphasizing the importance of educational activities in the educational process, especially in teaching of Hadith, and coming up with proposals that contribute to the development of educational activities for the Hadith.

Research importance arises from the following: the prominence of the Islamic religious sciences materials in Saudi Arabia curriculum, and its substantial role in shaping the active Muslim character; the effective and significant role of the educational activities in achieving the objectives of the curriculum. On the basis of a premise purports that all new must be subject to analysis and evaluation processes. There were no previous scientific studies that, to the best of the researcher's knowledge, dealt with the criteria of the educational activities in this curriculum.

\section{METHOD}

An analytical descriptive approach will be used in the research because of its appropriateness for the nature of the study.
A criteria card for the educational activities that the researcher will design, arbitrate and measure its validity and reliability, according to the adopted scientific steps. Studying the extent to which the criteria of educational activities are applicable to the activities of the Hadith book for the first intermediate grade (the activity book) in the general education schools in Kingdom of Saudi Arabia, the first semester, which include 52 activities.

\section{RESULTS AND DISCUSSIONS}

\section{Educational Activities}

They are interaction between learner and external conditions in environment in which they live (Bengio, Louradour, Collobert, \& Weston, 2009; Dewey, 2013; Tyler, 2013). Vogt \& Johnson (2011) defined activities of education and learning as every activity performed by teacher or learner, or by a visitor or a specialist, to achieve the educational or learning objectives and the comprehensive integrated growth of the learner, whether inside or outside classroom or school as long as it is performed under the supervision of the school. Da Graca Pimentel, Ishiguro, Kerimbaev, Abowd, \& Guzdial, (2001) defined them as mental or physical effort made by learner in order to achieve an objective. Al-Rashidi et al. (n.d.) defined them as all what student does with aim of learning, before, during or after educational situation, whether inside or outside school.

In this research, the educational activities mean (the operative definition) the tasks that student is required to perform, which are included in the activity book of Hadith course for the first intermediate grade, which are 52 activities.

\section{Criteria Required in Educational Activities}

There are a number of conditions and criteria that should be taken into account when selecting the educational activities and employing them in the school curricula. It is significantly noted and must be recognized by the researcher that there is a great difficulty in 
setting the criteria by which the educational activities will be judged, for these reasons: First, The enormous increase in the amount of knowledge available, or the so-called cognitive explosion that was provided by the available communication through various means of communication; readable, audio or visual. Second, The rapid social changes that always necessitate reconsidering the needs and objectives of young people, and the difficulty of selection caused by the difference in both the environment and learning possibilities.

1. What complicates the process of selecting the criteria of the educational activities is: the frequency of disagreements and opinions about the concept of the educational curricula, which are based on various opinions, considerations and basics. The diversity and multiplicity of opinions and educational philosophies in defining the concept of education, as well as the concept of curriculum, result from the multiplicity of schools and theories in this field from which it is emanating. This leads to hesitation in identifying the content and experiences. This leads to a sort of disagreements in the criteria according to which the content of the curriculum can be determined, and by which the educational activities and even their teaching methods, are selected.

2. The widening of the educational objectives and new cognitive areas for learning it requires that were not a part of or included in the curriculum.

3. The weakness of interaction with the educational technological progress, which has a multiplicity of teaching aids, which contributes to the pace of learning because of the abundance of existing technology, which unfortunately is not exploited and activated. This makes selecting the educational activities, which based on technology, and employing it, is clearly weak. Therefore, it was important to determine what is related to selecting the content, whether criteria or otherwise.

4. Content and educational activities share many things that are intertwined, and are inseparable from each other. They are like two bodies that are sticking and interrelated in the curriculum, other than the objectives and evaluation.

It is important that selecting forms of activity is based on several conditions or criteria that must firstly be present in those who select these criteria, and then in the criteria itself. The qualifications required in those who select these criteria are as follows: First, The curriculum planners should have a clear awareness of the relationship of the activity with the other elements of the curriculum, and be acquainted with all aspects of the educational renewal resulted from the educational developments, research and related studies.

Second is to have a conception of the philosophy of the curriculum of the activity in terms of its quantity and type. Third is to have a conception of the available material resources in light of which the necessary materials and equipment for this activity are prepared. Four is to be aware of the nature of the learner, and that the activity is related to their needs, interests and tendencies. Fifth is to be aware of the teacher's sufficiency and ability to successfully plan the activity with students.

As for the subject of criteria that are related to the activity, the researcher finds that what is referred to, from these criteria, in the curriculum books, may not exceed four axes:

1. Criteria which are available in the activity and related to the curriculum.

2. Criteria which are available in the activity and related to the student, their tendencies and abilities.

3. Criteria which are available in the activity and related to the activity in itself.

4. Criteria which are available in the activity and related to the environment in which the activity is performed.

Criteria which are available in the activities and related to the curriculum:

1. Educational activities should be purposeful, i.e. lead to achieving the 
objectives of the curriculum, i.e. activities can be selected according to the objectives set for the curriculum. If one of these objectives is to develop students' problem-solving skills, activities that contribute to achieve that objective should be provided. Activities must also be provided to achieve all the objectives. This can be ascertained by recording the objectives, then recording the proposed activities, and connecting each activity to the objective that serves this activity. If an objective appears to have no activity to serve, other activities may be suggested for that objective.

2. Educational activities should be appropriate for the content that the teacher is planning to teach, so organizing the content and educational activities allow using more than one learning method.

3. There are a direct and close connection between the other components of the curriculum and the educational activities, especially the objectives and content.

4. The activity should provide opportunities for the student to practice the activity or behavior to achieve a specific and desirable educational objective.

5. The necessity of selecting learning activities which are consistent with the theories and psychology of effective learning.

6. The learning activity should contribute to the development and improvement of the generalizations that are theoretically taught to the student.

7. Contributing to the development of more than one skill at a time, or achieving more than one objective if possible (Bakkenes, Vermunt, \& Wubbels, 2010; Parkay, Anctil, \& Hass, 2014).

Criteria available in the activities and related to the student's tendencies and abilities:

1. To be important and adequate, and associated with the learner, i.e. it is compatible with the student's benefit thus, providing the opportunity to satisfy the student's needs when practicing an activity or behavior toward learning and educational activities. If these activities do not satisfy these needs and interests it leads to undesired learning, it may even achieve the opposite of the objective of these activities. Learning is more effective when the learner is physiologically, psychologically and socially ready for it.

2. To be educative namely positive contributes to form student's good habits, modifying learner's behaviors, giving them proper trends and behaviors, and conformable to learning theories and psychology.

3. To be meaningful, so it complies with the student's reality, abilities and suitable for student's mental maturity level.

4. To contribute to achieving the learner's inclusive growth, and helps the learner to reach the maximum degree, taking into consideration the balance of developing learner's personality aspects.

5. To realize the student's participation in educational situations and their positivity toward learning process, as the aim is the participation of everyone in order that experience transfer to all learners, not just some of them.

6. Educational activity should have some sort of challenge to students' abilities, but they should be able to do them to lead them to new learning, or provide opportunities for them to apply what they have theoretically learnt previously.

7. The necessity of diversity of educational activities to consider individual differences through providing numerous opportunities for the students to choose whatever helps them to practice the activity.

Criteria available in the activities related to the activity itself:

1. To be continuous and progressive so they achieve learning accumulativeness and continuation, besides being characterized by gradual growth and increasing in nature which leads to deeper and more inclusive experiences which help students to reach the desired target. 
2. To be inclusive meaning that they help students to gain numerous interests such as caring about the society problems. It also leads to forming sound mental trends like linking causes with results, impartiality in judgment, objective observation for things and other.

3. To achieve the integration and inclusiveness principle so they achieve results in all objectives (information, skills, trends and tendencies) and include the entire curriculum to be taught.

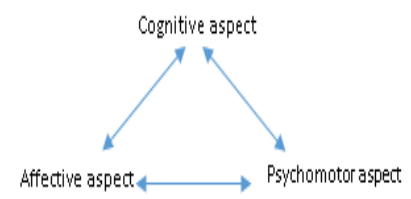

Figure 1: Experience Aspects System

4. The diversity of activities according to the education stage, so there are activities to begin learning, activities to develop it then activities to emphasize and conclude it. The forms and sources of activity vary so they are individual and collective, inside and outside the class, auditory, visual, motor, preliminary and final, etc.

5. To be practical so that the student benefits from it in dealing with new realities in their life, not just redundancy of information.

6. Educational activities to be practically applied with potentials available in the environment whether specialized human potentials (teachers and supervisors), formal (related to class room and school environment) or available materials (materials and equipment) so they benefit the learners in a way suits the efforts, time and spending exert in them.

7. Educational activities to be flexible and attractive.

8. To meet the balance criteria, so they become a mean of achieving objectives not an end.

Criteria related to the environment in which the student lives and performs the activity:

1. To be meaningful, i.e. they conform to the student's reality, fit their abilities and take into account the interests, needs, traditions of the society.

2. To include knowledge, skills, attitudes, tendencies and values necessary for the students' life in their society.

3. To achieve the balance between the needs of individual's growth and the requirements of the society, so that they are appropriate for the conditions of both the students and the society in which they live and taking into account the environmental conditions of each society.

4. The activities should be suitable for the possibilities: physical and human available for the school environment and the society in which the student lives.

5. To be connected to life: This means selecting the activities that highlight the learner's relation with life and living in it.

To lay down these criteria used to select curriculum activities, it is necessary to clarify a number of points: First, It is important to understand that the curriculum consists of two different things which are: the content and the learning activities or the mental processes used by students in learning the content. Although in the learning process itself, these two parts are in a continuous interaction, i.e. a person cannot deal with the content without having an educational experience, it's necessary to distinguish between these two aspects when trying to identify or lay down objective criteria for selecting curriculum activities. For example, it is possible to process or deal with a content that has significance, indication and meaning in a way that leads to an improper learning, or using fruitful learning processes with a content that is unworthy of studying.

Second, some educational objectives can be served through the content, while other objectives can be supported by specific learning activities. Objectives that are described as knowledge acquisition (concepts, ideas and facts) can be supported by selecting the content. On the other hand, achieving objectives such as thinking, skills and attitudes cannot be done only by testing and organizing the content (Anderson et al., 2001; 
Marzano, 2001; Marzano \& Kendall, 2006). It is noted, to the best of the researcher's knowledge, that there was no mention of the evaluation of the educational activities, nor about how to measure the achievement of acquiring experience that is the fruit of these activities, and nor how it can be developed. But all that have been written, even about the criteria, were general writings that need a kind of particularization in the form of criteria that can be measured to achieve the fruit from these criteria in the evaluation and improvement of the educational activities.

The main question of this paper was to which extent the activities of the subject of Hadith, stated in the Curriculum Document (2006) for the first intermediate grade meet the criteria of the educational activities. The new Islamic religious sciences curricula document of Kingdom of Saudi Arabia was worked out after four years of work, discussion and arbitration (1418-1421 AH). This document has been activated in (1423 $\mathrm{AH})$, then it was developed and in (1425 $\mathrm{AH})$ the primary and the intermediate grades had their own document.

\section{First Question of the Study}

In order to answer the first question of the study: What criteria should be provided in the educational activities of the Hadith curriculum for the first intermediate grade? The phases of work were as follows: After examining the main objectives of teaching Islamic religious sciences for public education and the objectives of teaching the Islamic religious sciences for the intermediate gradesthe researcher found-the necessity of adding more objectives for including closely related and methodical elements to complete laying down the criterion in a proper scientific way. Those objectives include some science skills and skills necessary to be learned, in order to gain benefit from the holy Hadith, those objectives are as follows:

Among the main objectives of teaching the Islamic religious sciences for the intermediate grades (Ministry of Education):
1. The student starts thinking and meditating on the universe and the creatures exist in it, recognizing Allah's gifts, thanking Him for those gifts and using them well.

2. The student realizes the importance of Arabic, its status in the religion, be proud of it and commits to speak it.

3. The student directs their tendencies, powers and capabilities to good destination.

4. The student uses their time in a good and useful way.

After those additions to control the tool which the research is based on, the following had to be clarified:

1. When comparing the objectives with the content, we find that there are specific objectives for each grade; some for the third intermediate grade and others for the second intermediate grade because of being stated in the main objectives list for both of them. This explains the results, after filling the tool and applying it on the objectives, which showed that most of the objectives were achieved in medium or weak degree.

2. The activity alone does not achieve all the objectives. Some of the objectives are achieved through the content. Some through both the content and the activity, and the rest are achieved through the activity only. That is what stated in many of the books discussed the ways of achieving the objectives of any curriculum. Some of them Douglass \& Shaikh (2004) said: Both the content and experiences are not indispensable, as the content achieves part of the objectives and the experiences achieve the other part.

The objectives, which are described as an acquisition of knowledge; (concepts ideas - facts), can be achieved through the content. At the same time, the ideas related to thinking, skills and tendencies require going through certain experiences which provide the opportunity to practice the target behavior. This explains the 
results that the researcher came to after applying the tool, for example, the objective (5) which is following the righteous forefathers was weakly achieved as its arithmetical average was (1.90), this objective can be achieved through cognitive side, so the content is more suitable to achieve this objective than the activity.

3. It is important to have criteria known as general criteria of activities to judge and define the quality of the activity. These criteria were mentioned in the books of people of experience known as the general criteria of good educational activity. These criteria are to be demonstrated after analyzing the objectives, with Allah's help.

4. There is a relation between some of the growth characteristics and educational activity, which should be considered when configuring the criteria as it is shown when discussing the stage characteristics (Farooq, 2013; Hashim, 2007).

Configuring the criterion or the tool was according to all above notices, with Allah's help. The first form of the tool was drafted and submitted to arbitrators. After that, there was the final form as shown in the next results.

Second Question of the Study
The answer to the second question of the study: To which extent the educational activity criteria are verified in the activity book attached to the book of Hadith for the first intermediate grade. The tool was applied through all the activities and the results were as follows:

Table 1. Arithmetical Averages and Their Descending Order to Determine the Most Important Criteria Available in the Activities

\begin{tabular}{lcc}
\hline \multicolumn{1}{c}{ Criteria } & $\begin{array}{c}\text { Arithmetical } \\
\text { Average }\end{array}$ & Order \\
\hline $\begin{array}{l}\text { Criteria related to growth } \\
\text { characteristics }\end{array}$ & 3.47 & 2 \\
$\begin{array}{l}\text { Criteria related to activity and } \\
\text { its general mechanisms }\end{array}$ & 3.13 & 3 \\
$\begin{array}{l}\text { Criteria related to the concept } \\
\text { of science }\end{array}$ & 3.87 & 1 \\
Total degree of the criteria & $\mathbf{3 . 4 9}$ & \\
\hline
\end{tabular}

*The average is out of 5 degrees

Thus, it is clear that the criteria are highly verified in all the axes of the criterion, whose arithmetic average was (3.49). All the axes were close at the degree of verification. The highest axis was the one related to the concepts of science whose arithmetic average was (3.87), which is a high degree of verification. The axis of activity mechanisms was the lowest among them. Its arithmetic average was (3.13), which is a medium degree of verification, while the rest of the axes had a high degree of verification. The reasons why the degree of verification in some axes is medium or an axis is higher than the other will be clarified through detailing each axis.

\section{The First Axis: The Criteria for the Characteristics of Growth}

Table 2. Recurrences, Percentages, Arithmetic Averages and Their Descending Order According to the Availability of Criteria Related to the Growth Characteristics of Activities

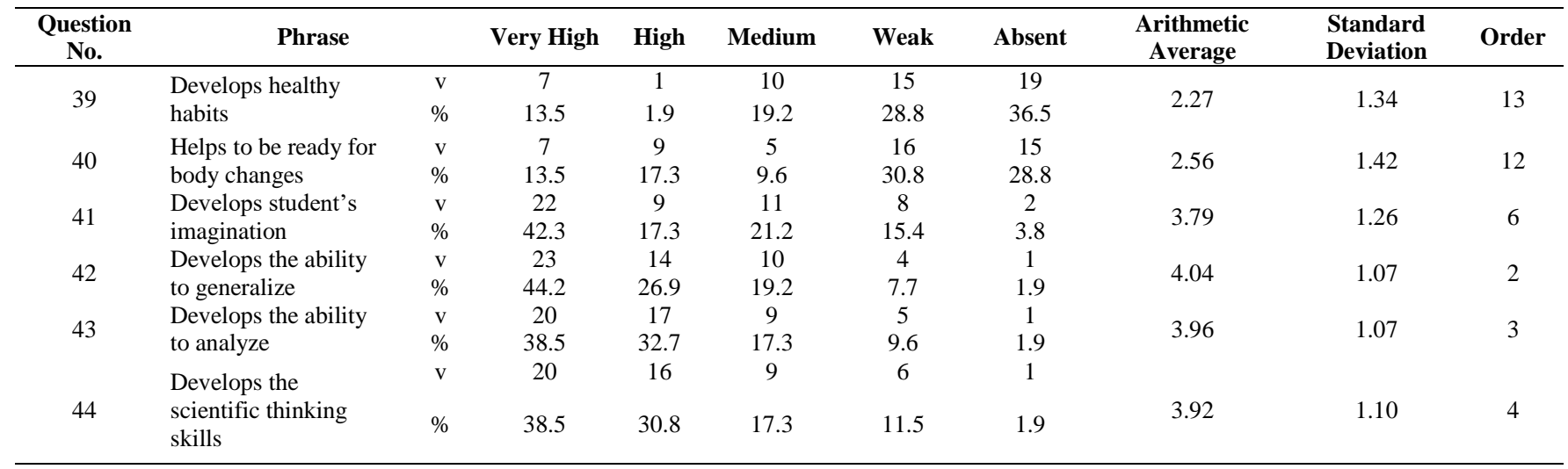




\begin{tabular}{|c|c|c|c|c|c|c|c|c|c|c|}
\hline $\begin{array}{l}\text { Question } \\
\text { No. }\end{array}$ & Phrase & & Very High & High & Medium & Weak & Absent & $\begin{array}{l}\text { Arithmetic } \\
\text { Average }\end{array}$ & $\begin{array}{l}\text { Standard } \\
\text { Deviation }\end{array}$ & Order \\
\hline \multirow[b]{2}{*}{45} & \multirow[b]{2}{*}{$\begin{array}{l}\text { Develops self- } \\
\text { confidence }\end{array}$} & $\mathrm{v}$ & 26 & 14 & 6 & 6 & & \multirow[b]{2}{*}{4.15} & \multirow[b]{2}{*}{1.04} & \multirow[b]{2}{*}{1} \\
\hline & & $\%$ & 50.0 & 26.9 & 11.5 & 11.5 & & & & \\
\hline \multirow[b]{2}{*}{46} & & $\mathrm{v}$ & 17 & 7 & 5 & 17 & 6 & \multirow[b]{2}{*}{3.23} & \multirow[b]{2}{*}{1.49} & \multirow[b]{2}{*}{11} \\
\hline & $\begin{array}{l}\text { Helps to achieve } \\
\text { emotional balance }\end{array}$ & $\%$ & 32.7 & 13.5 & 9.6 & 32.7 & 11.5 & & & \\
\hline 47 & $\begin{array}{l}\text { Develops respect for } \\
\text { parents }\end{array}$ & $\begin{array}{l}\mathrm{v} \\
\%\end{array}$ & $\begin{array}{c}7 \\
13.5\end{array}$ & $\begin{array}{c}1 \\
1.9\end{array}$ & $\begin{array}{c}4 \\
7.7\end{array}$ & $\begin{array}{c}13 \\
25.0\end{array}$ & $\begin{array}{c}27 \\
51.9\end{array}$ & 2.00 & 1.39 & 14 \\
\hline 48 & $\begin{array}{l}\text { Develops privacy and } \\
\text { independence } \\
\text { Develops love of }\end{array}$ & $\begin{array}{l}\mathrm{v} \\
\% \\
\mathrm{v}\end{array}$ & $\begin{array}{c}17 \\
32.7 \\
22\end{array}$ & $\begin{array}{c}11 \\
21.2 \\
9\end{array}$ & $\begin{array}{c}13 \\
25.0 \\
6\end{array}$ & $\begin{array}{c}7 \\
13.5 \\
14\end{array}$ & $\begin{array}{c}4 \\
7.7 \\
1\end{array}$ & 3.58 & 1.29 & 10 \\
\hline 49 & $\begin{array}{l}\text { Develops love of } \\
\text { cooperation with } \\
\text { others }\end{array}$ & $\%$ & 42.3 & 17.3 & 11.5 & 26.9 & 1.9 & 3.71 & 1.32 & \multirow[t]{2}{*}{7} \\
\hline \multirow[b]{2}{*}{50} & Develops the principle & $\mathrm{v}$ & 22 & 8 & 8 & 13 & 1 & \multirow[b]{2}{*}{3.71} & \multirow[b]{2}{*}{1.30} & \\
\hline & $\begin{array}{l}\text { of discussion with } \\
\text { others }\end{array}$ & $\%$ & 42.3 & 15.4 & 15.4 & 25.0 & 1.9 & & & 7 \\
\hline 51 & $\begin{array}{l}\text { Develops tolerance } \\
\text { with others }\end{array}$ & $\begin{array}{l}\mathrm{v} \\
\%\end{array}$ & $\begin{array}{c}21 \\
28.8\end{array}$ & $\begin{array}{c}10 \\
11.5\end{array}$ & $\begin{array}{c}6 \\
19.2\end{array}$ & $\begin{array}{c}15 \\
40.4\end{array}$ & & 3.71 & 1.27 & 7 \\
\hline 52 & $\begin{array}{l}\text { Develops respect for } \\
\text { others }\end{array}$ & $\begin{array}{l}\mathrm{v} \\
\%\end{array}$ & $\begin{array}{c}23 \\
44.2\end{array}$ & $\begin{array}{c}13 \\
25.0\end{array}$ & $\begin{array}{c}4 \\
7.7\end{array}$ & $\begin{array}{c}12 \\
23.1\end{array}$ & & 3.90 & 1.21 & 5 \\
\hline \multicolumn{8}{|c|}{ The General Average of the Criterion } & \multicolumn{3}{|c|}{3.47} \\
\hline
\end{tabular}

The above table shows that there is no phrase of the growth was very highly verified which requires attention and consideration from those in charge and it is not enough to be just one objective. It shows that the highly verified phrases ordered according to their arithmetic average are:

Table 3. The Verified Phrases Ordered according to Their Arithmetic Average

\begin{tabular}{clc}
\hline No & \multicolumn{1}{c}{ Phrase } & $\begin{array}{c}\text { Arithmetic } \\
\text { Average }\end{array}$ \\
\hline 1 & Develops self-confidence & 4.15 \\
2 & Develops the ability to generalize & 4.04 \\
3 & Develops the ability to analyze & 3.96 \\
4 & $\begin{array}{l}\text { Develops the scientific thinking } \\
\text { skills }\end{array}$ & 3.92 \\
5 & Develops respect for others & 3.90 \\
6 & Develops student's imagination & 3.79 \\
7 & $\begin{array}{l}\text { Develops love of cooperation with } \\
\text { others }\end{array}$ & 3.71 \\
8 & $\begin{array}{l}\text { Develops the principle of } \\
\text { discussion with others }\end{array}$ & 3.71 \\
9 & $\begin{array}{l}\text { Develops tolerance with others and } \\
10\end{array}$ & $\begin{array}{l}\text { Develops privacy } \\
\text { independence a }\end{array}$ \\
\hline
\end{tabular}

This shows that the mental and social aspect was verified more than the others. This supports what was concluded that once the activities develop the student's imagination and creativity, they can reach the new and urges to ask students always questions that develop their thinking. Al-Sharaf (2013) recommends in his research to pay attention to the useful activities in the innovative aspect.

He emphasized the importance of reconsidering the value of the educational activity and giving it the importance it deserves as an essential component of the educational process (Mahoney, Cairns, \& Farmer, 2003; Schutz, Hong, Cross, \& Osbon, 2006; Tikka, Kuitunen, \& Tynys, 2000). It is clear that a part of the emotional aspect was of medium verification through the verification degree of the following element:

Table 4. The Medium verification Degree of Emotional Aspect

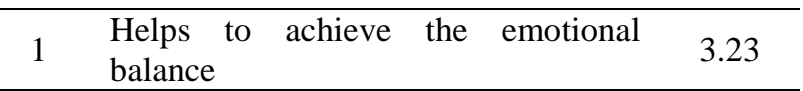

This can be explained by saying that the emotional balance and the related behaviors was the center of a whole class unit in the course of Hadith for the second intermediate grade so we find that the objectives of this unit as stated in the curriculum document are (Curriculum Document, 2006):

1. The student knows the reality of the good power.

2. The student follows the Islamic religious ways to overcome their anger. 
3. The student knows the judgment of harming others and avoids it.

4. The student knows that oppressing others is not of good power.

Most of the phrases related to the body aspect were of a weak degree as follows:

Table 5. The Phrases related to the Body Aspect

\begin{tabular}{lll}
\hline 1 & Helps to be ready for body changes & 2.56 \\
\hline 2 & Develops healthy habits & 2.27 \\
3 & Develops respect for parents & 2.00 \\
\hline
\end{tabular}

The reason for that is that caring of the body is among the objectives of teaching Hadith for the third grade as stated in the curriculum document (Curriculum Document, 2006). We previously explained that caring of health and body was included in a whole unit in the third grade as in the Curriculum Document (2006).
As for what is related to respect for parents, the student had a share of that in the jurisprudence and behavior subject at the primary stage, and was among the general objectives of teaching jurisprudence and behavior in the Curriculum Document (2006).

There will be a very clear reference to this through a whole unit in the second semester of this course in the unit of keeping good relations with relatives. In this unit there is a Hadith concerning that which is Abu Hurairah narrated that the Prophet said: May he be disgraced! May he be disgraced! May he be disgraced whose parents, one or both, attain old age during his life time, and he does not enter Jannah (by rendering being dutiful to them).

\section{The Second Axis: Criteria Related to Activity and Its General Mechanisms}

Table 6. Recurrences, Percentages and Arithmetic Averages and their Descending Order According to the Availability of the Activity and Its General Mechanisms

\begin{tabular}{|c|c|c|c|c|c|c|c|c|c|c|}
\hline $\begin{array}{l}\text { Question } \\
\text { No. }\end{array}$ & \multicolumn{2}{|l|}{ Phrase } & $\begin{array}{l}\text { Very } \\
\text { High }\end{array}$ & High & Medium & Weak & Absent & $\begin{array}{c}\text { Arithmetic } \\
\text { Average }\end{array}$ & $\begin{array}{l}\text { Standard } \\
\text { Deviation }\end{array}$ & Order \\
\hline \multirow{2}{*}{53} & Pays for information & $\mathrm{V}$ & 37 & 5 & 5 & 4 & 1 & \multirow{2}{*}{4.40} & \multirow{2}{*}{1.07} & \multirow{2}{*}{2} \\
\hline & & $\%$ & 71.2 & 9.6 & 9.6 & 7.7 & 1.9 & & & \\
\hline \multirow{2}{*}{54} & Helps to develop skills & $\mathrm{v}$ & 34 & 9 & 3 & 6 & & \multirow{2}{*}{4.37} & \multirow{2}{*}{1.03} & \multirow{2}{*}{3} \\
\hline & & $\%$ & 65.4 & 17.3 & 5.8 & 11.5 & & & & \\
\hline \multirow{2}{*}{55} & Helps to achieve & $\mathrm{V}$ & 39 & 9 & 2 & 2 & & \multirow{2}{*}{4.63} & \multirow{2}{*}{0.74} & \multirow{2}{*}{1} \\
\hline & objectives & $\%$ & 75.0 & 17.3 & 3.8 & 3.8 & & & & \\
\hline \multirow{2}{*}{56} & Written language suits & $\mathrm{v}$ & 30 & 6 & 10 & 5 & 1 & \multirow{2}{*}{4.13} & \multirow{2}{*}{1.16} & \multirow{2}{*}{5} \\
\hline & student's understanding & $\%$ & 57.7 & 11.5 & 19.2 & 9.6 & 1.9 & & & \\
\hline \multirow[b]{2}{*}{57} & Takes into account the & $\mathrm{V}$ & 29 & 6 & 10 & 6 & 1 & \multirow[b]{2}{*}{4.08} & \multirow[b]{2}{*}{1.19} & \multirow[b]{2}{*}{6} \\
\hline & student's level of & $\%$ & 55.8 & 11.5 & 19.2 & 11.5 & 1.9 & & & \\
\hline \multirow[b]{2}{*}{58} & $\begin{array}{l}\text { language ability } \\
\text { Diversity of }\end{array}$ & $\mathrm{v}$ & 3 & 2 & & 2 & 45 & \multirow[b]{2}{*}{1.38} & \multirow[b]{2}{*}{1.09} & \\
\hline & implementation place & $\%$ & 5.8 & 3.8 & & 3.8 & 86.5 & & & 9 \\
\hline \multirow{2}{*}{59} & Participation of all & $\mathrm{V}$ & 3 & & 5 & 2 & 42 & \multirow{2}{*}{1.46} & \multirow{2}{*}{1.07} & \multirow{2}{*}{8} \\
\hline & students as a group & $\%$ & 5.8 & & 9.6 & 3.8 & 80.8 & & & \\
\hline \multirow[b]{2}{*}{60} & Individual & $\mathrm{v}$ & 43 & & & & 9 & \multirow[b]{2}{*}{4.31} & \multirow[b]{2}{*}{1.53} & \multirow[b]{2}{*}{4} \\
\hline & implementation of some & $\%$ & 82.7 & & & & 17.3 & & & \\
\hline 61 & Taking time into account & $\mathrm{v}$ & & & & 1 & 51 & 102 & 0.14 & 10 \\
\hline 01 & in implementation & $\%$ & & & & 1.9 & 98.1 & 1.02 & 0.14 & 10 \\
\hline 62 & Diversity in sensory & $\mathrm{v}$ & 2 & 2 & 5 & 3 & 40 & & & \\
\hline 62 & employment & $\%$ & 3.8 & 3.8 & 9.6 & 5.8 & 76.9 & 1.52 & 1.08 & 7 \\
\hline & The G & era & erage & e Crit & & & & & 3.13 & \\
\hline
\end{tabular}

It is clear from the above table that the very highly verified phrases in the criteria related to the activity and its general mechanisms are: 
Table 7. The Highly Verified Phrases of Emotional Aspect

\begin{tabular}{lll}
\hline 1 & Helps to achieve objectives & 4.63 \\
\hline 2 & pays for information & 4.40 \\
3 & Helps to develop skills & 4.37 \\
4 & Individual implementation of some & 4.31 \\
\hline
\end{tabular}

Although this percentage is high, especially with regard of information, it is not the objective of the activity to increase the student's information as much as it is keen to build learning experiences, and as for information, it is in the content not activity. This supports what Bakkenes et al., (2010); Duhaney (2000) concluded that educational activities should not be mere memorization and review of the information contained in the lesson, but should be concerned with the development of creative skills, and their role should not be merely confined to memorizing and remembering information.

As for what is related to the implementation of the activity, individual implementation was the predominant over most activities, although this percentage is high, it will give us a sign that cooperative education, competition and participation among students did not have a significant impact in the educational activities, which turned many of the activities to what is similar to homework, or the evaluation of students, and did not create a new kind of learning includes a kind of excitement or pleasure and interest, which may make -God forbid- activities mere ink on paper, have no exist. The study of al-Thabeti (2001) indicates that there are three factors that contribute to encouraging the student at the intermediate stage to participate in activities. One of these factors is the presence of friends participating in his or her activity. It is clear that the phrases of high degree were:

Table 8. The High Verification Degree of the Presence of Friends Participating in the Activity

\begin{tabular}{llll}
\hline 1 & $\begin{array}{l}\text { The written language } \\
\text { student's understanding }\end{array}$ & suites & 4.13 \\
\hline 2 & $\begin{array}{l}\text { Takes into account the student's } \\
\text { level of language ability }\end{array}$ & 4.08 \\
\hline
\end{tabular}

This is evident in the students' book of activity, but what the researcher noted under the unification of courses is that the language used is only one which may not be suitable for some students. Since the study is related to the curriculum of Hadith, it is good that whoever has a relationship with this subject to care about it. It is clear that the phrases that were absent and arranged according to the arithmetic average are:

Table 9. The phrases that were Absent and Arranged according to the Arithmetic Average

\begin{tabular}{llll}
\hline 1 & The diversity in sensory employment & 1.52 \\
\hline 2 & $\begin{array}{l}\text { The participation of all students as a } \\
\text { group }\end{array}$ & 1.46 \\
3 & $\begin{array}{l}\text { The diversity of the implementation } \\
\text { place }\end{array}$ & 1.38 \\
4 & $\begin{array}{l}\text { Taking into account the time in } \\
\text { implementation }\end{array}$ & 1.02 \\
\hline
\end{tabular}

There are several things explain that in the element of sensory diversity, it is clear to us the limitation to the sense of speech only, without using other senses such as looking, contemplating, watching or hearing. This may be explained by what is related to the curriculum itself or school, the ways and methods of education, the teacher's role, and may be the lack of preparations and the available place which may contribute to diversification, or this may be due to the traditional classroom teaching method used which is: inculcation, not using new methods of teaching, and we observe the absence of technology, as the focus is only on hearing, conversation or memorization.

The individual participation was predominant, as evident in the previous result, and would have the superficial effect that is not comparable to the impact of interactive teaching or student grouping, and perhaps students' lack of knowledge of the importance of these activities and their role in understanding the curriculum or the completion of the desired image, their weak ability to interact as a group, and the absence of dialogue and participation, which led to the adoption of the individual method. 
There was weakness of diversity of implementation place, the reason, the existence of rented and narrow schools, and the lack of spacious places for practicing these activities. The activities did not stipulate the implementation to be external as a trip or a visit or so, but was limited to the request for implementation without specifying (Ahmad, 2001; Zia, 2007).

This is consistent with what Subramaniam \& Silverman (2007) came to in his study, that some activities cannot be implemented because of obstacles that prevent effective practice, including the teacher, the student, the curriculum and the school.

The school day may be overcrowded with many classes with which it is hard to change the implementation places. This is in line with Anzar (2003) opinion that teacher's lack of time prevents the aim of the activities. Abdullah \& Omar (2016) said that teachers' attitudes toward activities are positive. This gives hope for every planner of these activities once the teacher is given a good opportunity to do soon.

The reason for poor consideration of time in implementation may be explained by the following:

The Third Axis: Criteria Associated with the Concept of Science and Related to Hadith

Table 10. Recurrences, Percentages, Arithmetic Averages and Their Descending Order According to the Availability of Criteria Related to the Concept of Science and Related to Hadith in Activities

\begin{tabular}{|c|c|c|c|c|c|c|c|c|c|c|}
\hline Question No. & Phrase & & $\begin{array}{l}\text { Very } \\
\text { High }\end{array}$ & High & Medium & Weak & Absent & $\begin{array}{c}\text { Arithmetic } \\
\text { Average }\end{array}$ & $\begin{array}{l}\text { Standard } \\
\text { Deviation }\end{array}$ & Order \\
\hline \multirow[b]{2}{*}{63} & Develops & $\mathrm{v}$ & 23 & 15 & 8 & 6 & & \multirow[b]{2}{*}{4.06} & \multirow[b]{2}{*}{1.04} & \multirow[b]{2}{*}{6} \\
\hline & understanding & $\%$ & 44.2 & 28.8 & 15.4 & 11.5 & & & & \\
\hline 64 & $\begin{array}{l}\text { Helps to } \\
\text { compare texts }\end{array}$ & $\begin{array}{l}\mathrm{v} \\
\%\end{array}$ & $\begin{array}{c}30 \\
57.7\end{array}$ & $\begin{array}{c}9 \\
17.3\end{array}$ & $\begin{array}{c}10 \\
19.2\end{array}$ & $\begin{array}{c}3 \\
5.8\end{array}$ & & \multirow[t]{2}{*}{4.27} & \multirow[t]{2}{*}{0.97} & 4 \\
\hline \multirow[b]{2}{*}{65} & It is possible to & $\mathrm{v}$ & 38 & 9 & 3 & 2 & & & & \\
\hline & $\begin{array}{l}\text { infer by the } \\
\text { Hadith }\end{array}$ & $\%$ & 73.1 & 17.3 & 5.8 & 3.8 & & 4.60 & 0.77 & 2 \\
\hline \multirow{3}{*}{66} & Helps to apply & $\mathrm{v}$ & 41 & 8 & 1 & 2 & & \multirow{2}{*}{4.69} & \multirow{2}{*}{0.70} & \multirow[b]{2}{*}{1} \\
\hline & $\begin{array}{l}\text { the Hadith to } \\
\text { the real life }\end{array}$ & $\%$ & 78.8 & 15.4 & 1.9 & 3.8 & & & & \\
\hline & $\begin{array}{l}\text { Contributes to } \\
\text { linking the } \\
\text { benefits of the }\end{array}$ & $\mathrm{v}$ & 36 & 5 & 1 & 10 & & & & \\
\hline 67 & $\begin{array}{l}\text { Hadith and } \\
\text { solving } \\
\text { contemporary } \\
\text { problems }\end{array}$ & $\%$ & 69.2 & 9.6 & 1.9 & 19.2 & & 4.29 & 1.19 & 3 \\
\hline 68 & Helps to learn & $\mathrm{v}$ & 29 & 9 & 10 & 3 & 1 & 4.19 & 1.07 & 5 \\
\hline
\end{tabular}

1. Time of class is short; a class per week. This is in line with al-Shammari (2007) study. He mentioned that it is important to increase the time allotted to activities so that students can practice educational activities that suit their interests, satisfy their desires and develop their talents.

2. The large number of students.

3. Lack of available resources that save time to accomplish activities, which is in line with what al-Thenbity (n.d.) concluded that twenty most important problems facing the activity are the lack of material resources and raw materials, the lack of suitable place and the lack of students' awareness of the importance of activity.

Al-Shammari (2007) also referred to the need to prepare permanent headquarters for practicing educational activities, and providing tools, devices and materials by the Ministry of Education. 


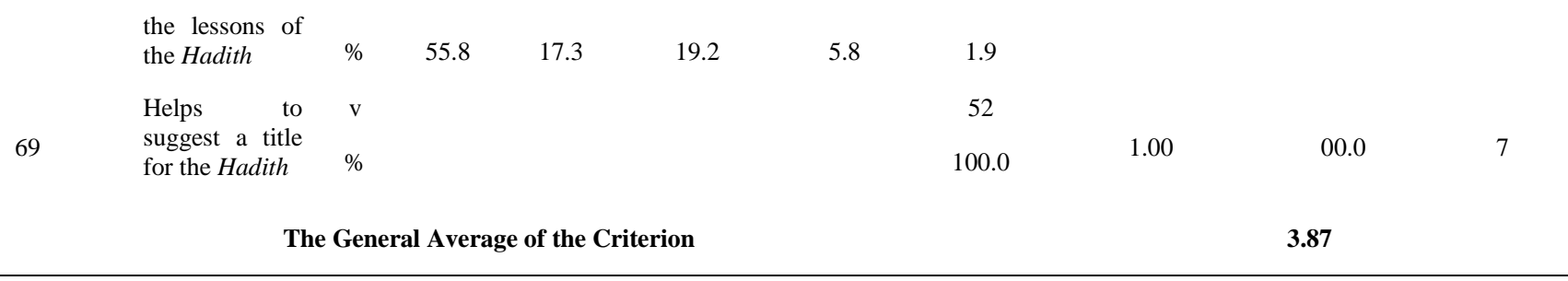

It is clear from the above table that the highly verified phrases are:

Table 11. The Highly Verified Phrases

\begin{tabular}{lll}
\hline 1 & Helps to apply the Hadith to the real life & 4.69 \\
\hline 2 & It is possible to infer the Hadith & 4.60 \\
3 & $\begin{array}{l}\text { Contributes to linking the benefits of the Hadith and solving } \\
\text { contemporary problems }\end{array}$ & 4.29 \\
4 & Helps to compare texts
\end{tabular}

This is a natural outcome that supports what was concluded by all who tackled the Hadith in their teaching or other which is that the Prophet's Hadith is taught to interact with people's issues and solve many of their problems, as al-Khawlada and Eid (2001)concluded when they talked about the educational media in Islamic education, and what they referred to when talking about global Islamic education, and its positivity in solving many of the global problems, or even in the application of the Hadith to reality, and these are of the characteristics of Islamic education. While it is clear that the phrases highly verified are:

Table 12. The Highly Verified Phrases of Islamic Characteristics

\begin{tabular}{lll}
\hline 1 & Helps to deduce lessons from Hadith & 4.19 \\
\hline 2 & Develops understanding & 4.06 \\
\hline
\end{tabular}

This supports what al-Suwaidi (2000) said in her research that the questions and activities focused primarily on understanding, then remembering and then application. While it is clear that the only missing phrase was:

Table 13. The Missing Phrase

\begin{tabular}{lll}
\hline 1 & $\begin{array}{l}\text { Contributes to helping to suggest a title } \\
\text { for the Hadith }\end{array}$ & 1.00 \\
\hline
\end{tabular}

The explanation for the absence of this element is reflected in the review of the textbook. It was found that the student is asked to choose a title for the Hadith from several options, or by proposing a title or requesting approval for the title proposed for the lesson, which naturally availed repeating it in the separate educational activities.

The researcher came to several results, the most important are:

1. The criteria for the study were verified to a high degree and an average of (3.49).

2. The achievement of the three axes that represented the tool was arranged as follows: a) The criteria associated with the concept of science were highly verified and with an average of $(3.87), b)$ The criteria for the characteristics of growth were highly verified and with an average of (3.47). c) The criteria related to the activity and its general mechanisms were verified in a medium degree and an average of (3.13).

3. The criteria for growth characteristics are verified, to varying degrees as follows: a) The observance of activities for psychological characteristics was highly verified in the mental, emotional and social aspect, medium and weak or absent in. b) The physical aspect is weak.

4. The criteria related to the activity and its mechanisms were verified as follows: a) A mechanism to classify the activity achieved by the student was very highly verified, b) What is relevant to the 
language in which the activity is written was highly verified, c) What is relevant to the diversity of the activity was weakly verified.

5. The criteria relating to the concept of Science were verified as follows: a) The objective of comparison among texts, the objective of inference, and applying the Hadith to new facts, and using the Hadith in solving contemporary problems, were very highly verified, b) The objective of public understanding of the Hadith, and the deduction of lessons was highly verified. c) The aim of proposing a title for the Hadith was absent.

\section{CONCLUSION AND RECOMMENDATION}

At the end of this paper, it is clear to all specialists and teachers who have a clear relationship with the curricula the need for educational activities as an integral part of the educational curriculum. It is useful for the educational process to involve integration between these activities of this scientific subject in Islamic education and other similar subjects such as Tafsir, 'Aqidah and Fiqh, then they are also linked to a number of other scientific subjects such as Mathematics, Science and other subjects such as History, thus a network of activities that complement each other and build the student comprehensively and completely.

We still have to be keen to innovate in the introduction of these activities through new templates suite the age and the technical generation of our students these days, as well as it is preferable to have new methods and images of these modern activities that keep pace with the era of social communication and infiltrate it and restore our students. In the light of the results of the research, the researcher makes some recommendations, which will help in developing educational activities in the modern curriculum for the first grade. The recommendations are:

1. Caring of whatever is related to the physical changes that will happen and instilling healthy habits through the Hadith.

2. Stipulating the diversification of activities implementing places and the identification of times of implementation that take individual differences in to consideration.

3. Increasing the quorum of the Hadith to two classes per week, because activity has a separate book which makes it necessary to deal with in a whole class, otherwise turned into something similar to homework the student does in their home, and this is the purpose of this book.

4. Putting references indicate the method of implementation in the student's book, like those in the teacher's guide.

5. Establishing a clear mechanism for cooperation with some parties where some activities can be implemented.

6. Caring of educating students about the concept of activity and the difference between it and the content and the benefit of each of them to students, in a language the students understand and feel its importance.

7. Differentiating between educational activities for male and female students, after the unification of content. It is more proper that the activities become for each sex according to nature and characteristic.

8. Establishing special headquarters for activities that contain many means of helping in the implementation of these activities and facilitate accomplishing them faster.

9. Motivating teachers who practice teaching activities to take this into account when assessing performance.

10. Forming special committees or appointing educational supervisors whose first task is to follow up educational activities in the Islamic religious courses, and evaluating them, and help teacher and student to pass all that may complicate the accomplishment of these activities.

11. Holding training courses for teachers, to explain and clarify the concepts of 
modern activity and new trends in the developed Islamic religious curricula, and to clarify the best ways and methods to teach them, and achieve their effectiveness in the learning educational environment.

12. An electronic version that contributes to supporting these activities and establishing their concepts through more comprehensive electronic diversity, and greater opportunities in dealing with modern technology and employing it for the good of student learning and the achievement of new experiences for them.

13. To benefit from the widespread media outreach and the creation of educational channels that broadcast a kind of programs that complement the educational curricula and encourage students to follow them.

It has been shown from this research that there are several suggestions, which may be the subject of research in future studies, these suggestions include:

1. A study similar to this study on the rest of the subjects of Islamic religious sciences in the intermediate stage which are (al-Qur'an and its interpretation, jurisprudence, and monotheism).

2. A comparative study among the educational activities of Hadith, jurisprudence and monotheism in achieving the general objectives of teaching Islamic religious sciences in the intermediate stage.

3. Studying the extent and sequence of experience in the educational activities of the Hadith in the intermediate stage.

4. The extent to which students interact with the educational activities of the Hadith in the book of activity and its impact on their educational achievement from the teachers and educational supervisors' point of view.

5. A proposed training program for Islamic education teachers to understand the mechanisms of educational activity.

6. Teachers and educational supervisors' attitudes to add educational activities to
Islamic education courses in the intermediate stage.

\section{REFERENCES}

Abdullah, A. H., \& Omar, M. C. (2016). A prolonged dilemma: Traditional curriculum of Arabic Rhetoric (Balaghah) in Malaysia. The Social Sciences, 11(6), 1008-1014.

Ahmad, I. (2001). Teaching Islamic studies in the non-Arab world: with or without Arabic? Journal of Muslim Minority Affairs, 21(2), 273-285.

Al-Sadan, I. A. (2000). Educational assessment in Saudi Arabian schools. Assessment in Education: Principles, Policy \& Practice, 7(1), 143-155.

Al-Sharaf, A. (2013). Developing scientific thinking methods and applications in Islamic education. Education, 133(3), 272-282.

Anderson, L. W., Krathwohl, D. R., Airasian, P. W., Cruikshank, K. A., Mayer, R. E., Pintrich, P. R., ... Wittrock, M. C. (2001). A taxonomy for learning, teaching, and assessing: A revision of Bloom's taxonomy of educational objectives, abridged edition. White Plains, NY: Longman.

Anzar, U. (2003). Islamic education: A brief history of madrassas with comments on curricula and current pedagogical practices. Paper for the University of Vermont, Environmental Programme.

Bakkenes, I., Vermunt, J. D., \& Wubbels, T. (2010). Teacher learning in the context of educational innovation: Learning activities and learning outcomes of experienced teachers. Learning and Instruction, 20(6), 533548.

Bengio, Y., Louradour, J., Collobert, R., \& Weston, J. (2009). Curriculum learning. In Proceedings of the 26th 
annual international conference on machine learning (pp. 41-48). ACM.

Graca Pimentel, M., Ishiguro, Y., Kerimbaev, B., Abowd, G. D., \& Guzdial, M. (2001). Supporting educational activities through dynamic web interfaces. Interacting with Computers, 13(3), 353-374.

Dewey, J. (2013). The school and society and the child and the curriculum. University of Chicago Press.

Douglass, S. L., \& Shaikh, M. A. (2004). Defining Islamic Education: Differentiation and Applications. Current Issues in Comparative Education, 7(1), 5-18.

Duhaney, D. C. (2000). Technology and the educational process: Transforming classroom activities. International Journal of Instructional Media, 27(1), 67-67.

Farooq, M. (2013). Disciplining the feminism: Girls' madrasa education in Pakistan. The Historian, 3(2).

Goodlad, J. I. (2013). School curriculum reform in the United States. In Curriculum Studies Reader E2 (pp. 69-78). Routledge.

Hashim, R. (2007). Intellectualism in higher Islamic traditional studies: Implications for the curriculum. American Journal of Islamic Social Sciences, 24(3), 92.

Jacobs, H. H. (2004). Getting Results with Curriculum Mapping. ERIC.

Jacobs, H. H. (2010). Curriculum 21: Essential education for a changing world. ASCD.

Kam, C.-M., Greenberg, M. T., \& Walls, C. T. (2003). Examining the role of implementation quality in schoolbased prevention using the PATHS curriculum. Prevention Science, 4(1), $55-63$.
Mahoney, J. L., Cairns, B. D., \& Farmer, T. W. (2003). Promoting interpersonal competence and educational success through extracurricular activity participation. Journal of Educational Psychology, 95(2), 409.

Marzano, R. J. (2001). Designing a New Taxonomy of Educational Objectives. Experts in Assessment. ERIC.

Marzano, R. J., \& Kendall, J. S. (2006). The new taxonomy of educational objectives. Corwin Press.

Millar, R. (2002). Towards a science curriculum for public understanding. Teaching Science in Secondary Schools, 113-128.

Parkay, F. W., Anctil, E. J., \& Hass, G. (2014). Curriculum leadership: Readings for developing quality educational programs. Prentice Hall.

Prokop, M. (2003). Saudi Arabia: The politics of education. International Affairs, 79(1), 77-89.

Rosen, E. (2008). The Muslim Brotherhood's Concept of Education. Current Trends in Islamist Ideology, 7(85), 115-29.

Rugh, W. A. (2002). Education in Saudi Arabia: choices and constraints. Middle East Policy, 9(2), 40-56.

Salehi, H., Davari, A., \& Yunus, M. M. (2015). Evaluation of an ESP Course of Qur'anic Sciences and Tradition. International Education Studies, 8(1), 29-37.

Schutz, P. A., Hong, J. Y., Cross, D. I., \& Osbon, J. N. (2006). Reflections on investigating emotion in educational activity settings. Educational Psychology Review, 18(4), 343-360.

Sedgwick, R. (2001). Education in Saudi Arabia. World Education News and Reviews, 16. 
Shea, N., \& Al-Ahmed, A. (2006). Saudi Arabia's Curriculum of Intolerance with Excerpts from Saudi Ministry of Education Textbooks for Islamic Studies. Center for Religious Freedom.

Subramaniam, P. R., \& Silverman, S. (2007). Middle school students' attitudes toward physical education. Teaching and Teacher Education, 23(5), 602611.

Tikka, P. M., Kuitunen, M. T., \& Tynys, S. M. (2000). Effects of educational background on students' attitudes, activity levels, and knowledge concerning the environment. The Journal of Environmental Education, 31(3), 12-19.

Tyler, R. W. (2013). Basic principles of curriculum and instruction. In
Curriculum Studies Reader E2 (pp. 60-68). Routledge.

Vogt, W. P., \& Johnson, B. (2011). Dictionary of statistics \& methodology: A nontechnical guide for the social sciences. Sage.

Yahya, M. A., Dakir, J., Amran, N. N., Noor, A. Y. M., Ibrahim, M., \& Nazri, M. A. (2017). Application of Hadith Memorization Methods in Teaching and Learning: The National University of Malaysia's Experiences. Turkish Online Journal of Educational Technology, 2017(October Special Issue INTE), 368-372.

Zia, R. (2007). Transmission of values in Muslim countries: Religious education and moral development in school curricula. In School knowledge in comparative and historical perspective (pp. 119-134). Springer. 